$\mathcal{E}_{\text {International }}^{\text {Insport Forum }}$

\title{
Asset Management for Sustainable Road Funding
}

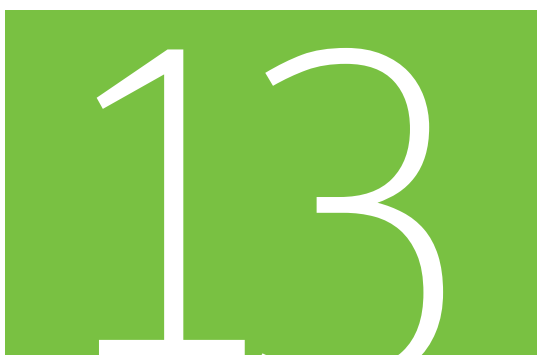

Discussion Paper 2013 13

Philippe Crist, Jari Kauppila International Transport Forum, Paris, France

José Vassallo

Universidad Politécnica de Madrid, Spain

Butch Wlaschin

Federal Highway Administration, Washington DC, USA 


\title{
Asset Management for Sustainable Road Funding
}

\author{
Discussion Paper No. 2013-13
}

\author{
Philippe CRIST \\ International Transport Forum at the OECD, Paris, France \\ J ari KAUPPI LA \\ International Transport Forum at the OECD, Paris, France \\ J osé VASSALLO \\ Universidad Politécnica de Madrid, Spain \\ Butch WLASCHIN \\ Federal Highway Administration, Washington DC, USA
}

May 2013 


\section{THE I NTERNATI ONAL TRANSPORT FORUM}

The International Transport Forum at the OECD is an intergovernmental organisation with 54 member countries. It acts as a strategic think-tank, with the objective of helping shape the transport policy agenda on a global level and ensuring that it contributes to economic growth, environmental protection, social inclusion and the preservation of human life and well-being. The International Transport Forum organises an annual summit of Ministers along with leading representatives from industry, civil society and academia.

The International Transport Forum was created under a Declaration issued by the Council of Ministers of the ECMT (European Conference of Ministers of Transport) at its Ministerial Session in May 2006 under the legal authority of the Protocol of the ECMT, signed in Brussels on 17 October 1953, and legal instruments of the OECD.

The Members of the Forum are: Albania, Armenia, Australia, Austria, Azerbaijan, Belarus, Belgium, Bosnia-Herzegovina, Bulgaria, Canada, Chile, China, Croatia, the Czech Republic, Denmark, Estonia, Finland, France, FYROM, Georgia, Germany, Greece, Hungary, Iceland, India, I reland, Italy, Japan, Korea, Latvia, Liechtenstein, Lithuania, Luxembourg, Malta, Mexico, Moldova, Montenegro, the Netherlands, New Zealand, Norway, Poland, Portugal, Romania, Russia, Serbia, Slovakia, Slovenia, Spain, Sweden, Switzerland, Turkey, Ukraine, the United Kingdom and the United States.

The International Transport Forum's Research Centre gathers statistics and conducts co-operative research programmes addressing all modes of transport. Its findings are widely disseminated and support policymaking in Member countries as well as contributing to the annual summit.

\section{Discussion Papers}

The International Transport Forum's Discussion Paper Series makes economic research, commissioned or carried out at its Research Centre, available to researchers and practitioners. The aim is to contribute to the understanding of the transport sector and to provide inputs to transport policy design. The Discussion Papers are not edited by the International Transport Forum and they reflect the author's opinions alone.

The Discussion Papers can be downloaded from:

www. internationaltransportforum. org/jtrc/DiscussionPapers/jtrcpapers. html

The International Transport Forum's website is at: www.internationaltransportforum.org

For further information on the Discussion Papers and other JTRC activities, please email: itf.contact@oecd.org 
TABLE OF CONTENTS

FOREWORD 5

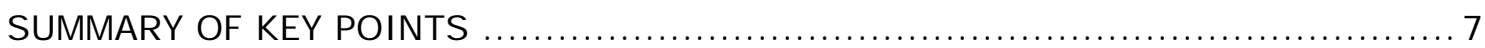

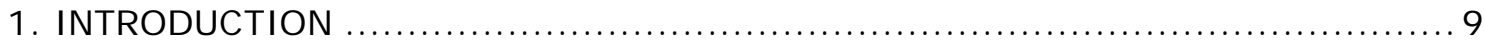

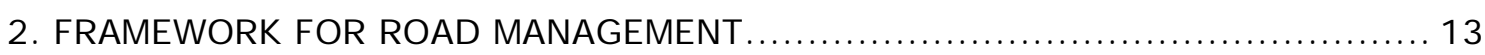

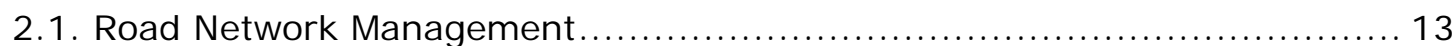

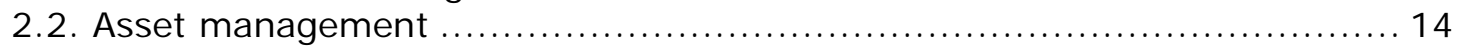

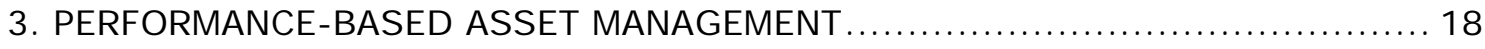

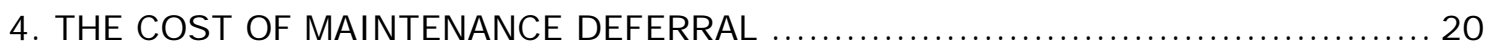

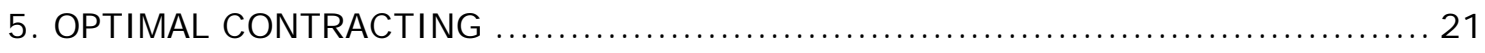

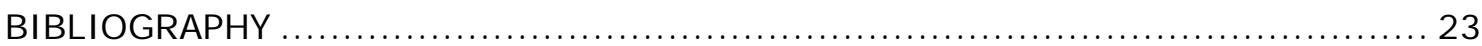





\section{FOREWORD}

This paper lays out a framework for managing complex asset systems, such as road networks, with a view to optimising life-cycle value of the asset base. It is based on discussions at the International transport Forum Roundtable on Sustainable Road Funding held in Paris 25-26 October $2012^{1}$ and includes inputs from the ITF working Group on Infrastructure Adaptation to Extreme Weather and Climate Change.

1. The discussion papers prepared for the roundtable are available at http://internationaltransportforum. org/itrc/roundtables.html.

The authors would like to thank Dr. Mark Harvey, Australian Department of I nfrastructure and Transport Bureau of Infrastructure, Transport \& Regional Economics, Prof. Matthew Karlaftis, National Technical University of Athens and Dr. Jan-Eric Nilsson, Swedish National Road and Transport Research Institute for their contributions and comments of the Roundtable participants. 



\section{SUMMARY OF KEY POI NTS}

- Road networks represent one of the principal asset systems held by national and regional governments yet data on asset condition and value is consistently lacking in a number of jurisdictions. This complicates the task of assessing road network condition and optimising expenditure on maintenance, refurbishment and new investment.

- Introducing an asset management approach to road network management and specifying explicit links to strategic budgets are essential for transport authorities to arbitrate among needs, vulnerabilities and trade-offs.

- Asset management is often misleadingly understood as maintenance management. This definition, however, is too narrow. Asset management is related to delivering pre-defined goals, normally measured in terms of outcomes or service levels.

- The overall aim of asset management is to optimise the service level delivered by infrastructure over its life-cycle. The focus of management should be on value to users or customers and not solely, nor even primarily, on cost or assetreplacement cost perceived by the infrastructure provider.

- Optimal service levels are not a static construct. They evolve over time (both over the short- and long-term) and in response to a number of interacting factors asset management strategies should explicitly account for this.

- When budgets are tight, funding for road maintenance is often postponed on the expectation (and hope) that a lack of maintenance will not necessarily lead to immediate asset failure and network disruption. The cumulative impact of deferred maintenance, however, increases asset and network vulnerability to local or systemic disruptions.

- In the long term, deferring maintenance can make roadway costs much greater than indicated by current expenditures. The challenge is to provide additional information on the value of roadway facilities and the costs associated with deferred spending, in order to bring these to the attention of decision makers.

- Countries are increasingly outsourcing maintenance and operations and using performance based contracts for achieving sustainable financing for road maintenance and operations projects. There is no one type of contract for all situations as the type of contract depends on specific circumstances of individual projects. This emphasises the importance of developing tools for the tendering agency to evaluate pros and cons of different contracting approaches. 



\section{I NTRODUCTI ON}

Road networks require significant long-term investments and represent one of the principal assets held by national and regional governments. In Europe alone, the 5.5 million kilometre road network constitutes one of the largest assets of the European Community. Countries invest in roads because they are economically important. In Europe, for example, over $75 \%$ of freight transport is carried by road while road transport covers nearly $90 \%$ of the total inland passenger transport (OECD/ITF 2012). While many countries already have relatively mature road networks (in various levels of repair), overall future road infrastructure needs are considerable. Current global levels of road investment needs will not remain constant but rather will grow as incomes and demand in developing countries progress. According to the McKenzie Global Institute, USD 16.6 trillion will be required to meet global road investment needs by 2030 (McKenzie Global Institute 2013).

Road networks are key enablers of economic growth, productivity and social well-being. Well-functioning networks contribute to prosperity on many fronts by, for example, enabling growth through reduced business costs, improving access to markets and improving labour mobility. High quality road system performance impacts people's quality of life by reducing travel times, enabling travel for leisure, reducing risk of crashes and decreasing the impact of traffic on environment.

Like any physical asset, roads also require continuous attention in terms of maintenance, to counter deterioration. Indeed, once new infrastructure has been built, it will need to be operated and maintained over its useful life in order to deliver expected benefits. Many road asset systems may seem "perpetual" in that they are in the "operate and maintain" part of their lifecycle with no expectation of closure, decommissioning, deconstruction or demolition (CIRIA 2009). It is not uncommon for much of the existing infrastructure stock to have been in service for longer than the current design life of equivalent assets as is the case in the United Kingdom (CIRIA 2009). Funding of operations and maintenance are a direct result of capital spending decisions and may be expected to extend indefinitely into the future for many assets - maintenance expenditures should be therefore taken into account over an indefinite (life-cycle of the infrastructure) timeframe for these assets and asset systems.

Another point well worth noting is that asset systems such as roads are in fact a collection of individual, interconnected asset sub-classes that each play a role in delivering expected performance outcomes. For instance, the UK Highways Agency has identified 25 asset components divided into 7 asset sub-classes that are critical for the "highway asset" to function properly and meet users' service needs and expectations (Figure 1). These asset components all have different lifespans and maintenance/refurbishment schedules that must be adhered to in order to minimise the risk of asset failure and/or service disruption. Assets system components typically outlast political and budgetary cycles and for many longer-life assets, extend into timescales where conditions cannot at this time be accurately predicted (e.g. future demand, climate impacts). 
Figure 1. UK Highway Agency Asset System: Component lifespans

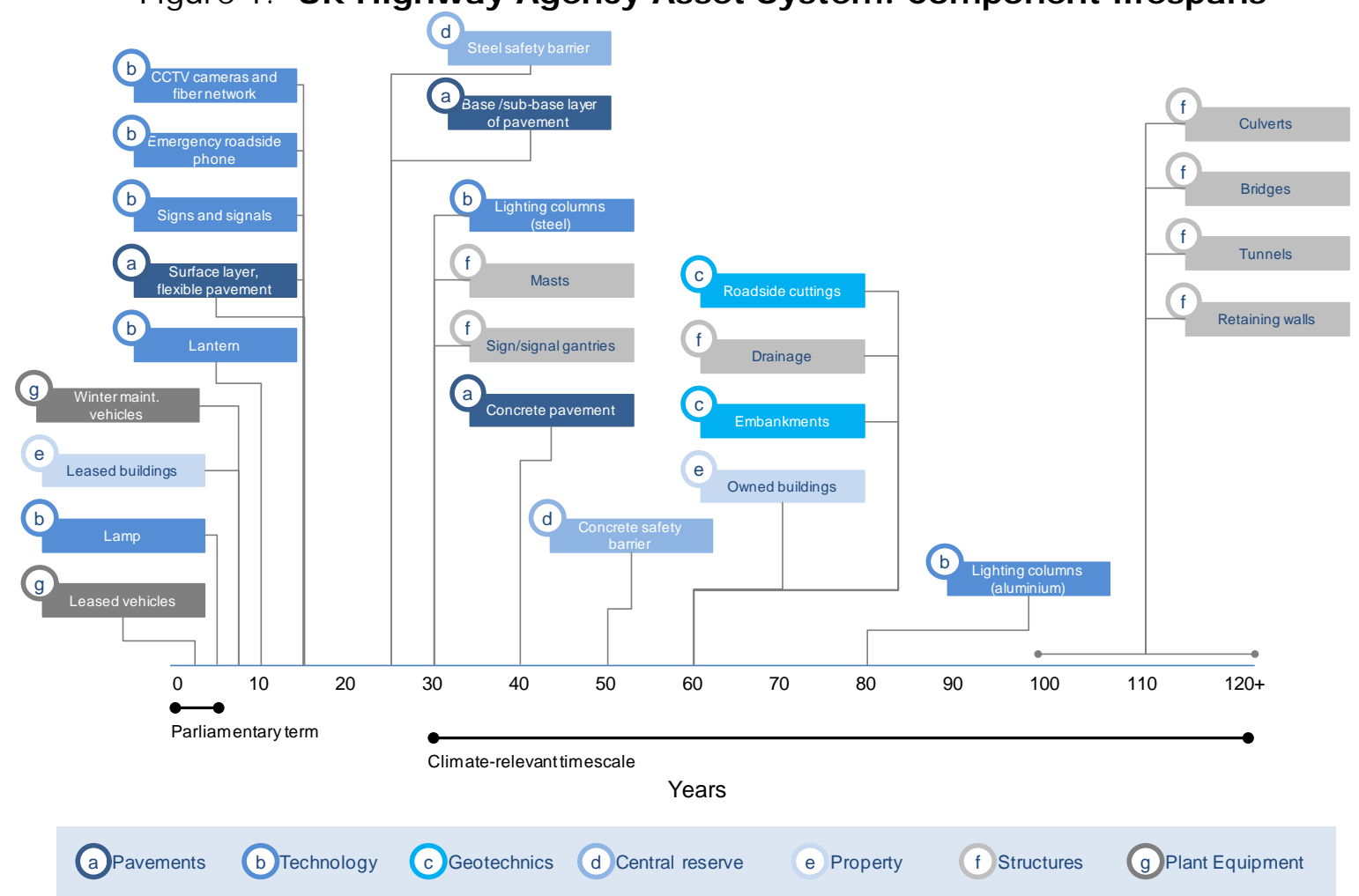

Source: (UK Highways Agency 2011).

Another issue is that uncertainty regarding the impacts of climate change complicates the task of determining optimal levels of road investment. Road system assets are built according to engineering design standards that incorporate various climate-related factors such as temperature, precipitation, humidity and wind. Assets located in coastal and estuarine zones also incorporate sea-level parameters. The risk under a changing climate regime is that some of these parameters may change beyond the design specifications incorporated into the existing asset base and that are still used for new construction. This may lead to accelerated deterioration or outright failure of critical assets. Further complicating the situation is that there is little certainty as to how global climate change may manifest itself at the regional level in terms of the frequency and strength of specific asset-damaging phenomena. This uncertainty affects the scale of initial investments, the return period (and therefore cost) for refurbishments and the impact of maintenance. Climate change may erode the potential benefits of some vulnerable assets and improve the cost-benefit profile of less vulnerable alternatives.

For some asset components, the risk is minimal since their design life is shorter than the period over which changes in climate may manifest themselves - e.g. in the case of road surfaces. For other asset subcomponents, the risk is significant since their design life (or effective period of use in the case of existing assets) extents well within climate timescales (e.g. 50+ years). Road owners and managers must assess how changing climate and the incidence of new patterns of extreme weather events may lead to system-critical failures - e.g. culvert failures under extreme rainfall giving rise to road washouts. In this respect an asset management framework can be the basis on which climate risk management strategies are built. 
Meeting maintenance, refurbishment and ultimately replacement needs across the host of asset subclasses is a complex process that requires pluri-annual budget streams. Countries have adopted sometimes different approaches to addressing these funding needs but generally, budgets and programmes for the road sector have been prepared on a historical basis in which each year's budget is based upon previous years' budgets rather than on objective needs-based data. Under such approaches, there is no way of telling whether funding levels are adequate.

Many developed countries have raised concerns regarding the state of existing road infrastructure and its impacts on the competitiveness of the economy and well-being in general. This general concern about underfunding and especially the poor condition of existing infrastructure is difficult to verify due to lack of data on the condition of road assets. Data on the condition of some parts of the road asset system may be available (road pavements, bridges, tunnels) but for many other critical asset classes (culverts, drainage, embankments, geotechnical substrata) it is either missing or difficult to assess due to a lack of centralised data collection and storage.

Even if data on asset condition were broadly and consistently collected, the task of converting inventory data into monetary terms remains challenging on both a material and methodological basis. In order to value asset inventories one would, in theory, need prices from markets in which the assets are regularly, actively and freely traded. This may be the case for some asset classes (vehicles, buildings) but is certainly not the case for many critical road system assets (pavements, drainage, bridge pilings, culverts, road cuts, etc). In the absence of market prices two alternatives are available: net present value or perpetual inventory methodology (PIM). The former sets the value of the asset to the present (discounted) value of future economic benefits from a given value. The challenge here is that as noted earlier, many assets continue to provide (residual) value long past their design life and/or their book value has been discounted to zero. PIM approximates capital stock value by accumulating and revaluing acquisitions minus disposals of assets over their lifetime and adjusting for factors such as depreciation and destruction due to natural disasters, etc. PIM captures the service value of (near) permanent assets as the assets' "current replacement cost" or "depreciated replacement cost" - e.g. what would need to be spent to replace the asset in its current condition (see OECD, 2009). Few countries or road authorities approach asset valuation in this manner.

When budgets are tight, funding for road maintenance is often postponed on the expectation (and hope) that a lack of maintenance will not necessarily lead to immediate asset failure and network disruption. The cumulative impact of deferred maintenance, however, increases asset and network vulnerability, for instance to unexpected or extreme meteorological events which may occur more frequently under a changing climate regime. At the same time, there is pressure to improve network performance due to the combined effect of increased traffic and greater expectations regarding service levels. In some cases, a failure to answer these challenges has led to a number of negative impacts, among them notably congestion and traffic disruptions which have exacerbated system unreliability.

Robinson and Roberts (1982) have estimated the relative discounted life-cycle costs of construction, maintenance and vehicle operation under different maintenance spending scenarios. Under normal conditions, a road in a good condition requires maintenance spending of about $2 \%$ of the total discounted costs, including vehicle operation. However, halving maintenance is likely to increase users' vehicle operating costs by $15 \%$ while completely neglecting maintenance will increase annual vehicle operating costs for users by $50 \%$. 
In this context, the main question for road decision makers then becomes:

What is the mix and timing of strategies, including maintenance, operation and new construction, needed to guarantee optimal service levels on the network over the life-span of its individual component assets?

Introducing an asset management approach to road network management and specifying explicit links to strategic budgets are essential for transport authorities to arbitrate among needs, vulnerabilities and trade-offs. Putting in place a comprehensive asset management program is therefore a first step. This paper explores these issues by discussing the concepts of network management (Section 2.1) and asset management (Section 2.2). Section 3 addresses the need to tie asset management to asset performance and how to measure the latter. Section 4 touches on the importance of understanding and capturing the cost of maintenance deferral. Finally, Section 5 discusses different ways of designing contracts for tendering maintenance and construction.

Strategic asset management should have a link to long-term financial planning as existence of a sustainability of funding sources is a key to maintaining performance (see Nemoto 2012). Although acknowledged as an important element of sustainable road funding, this paper does not discuss sources of funding. For views on this issue, see for example ECMT (2007). 


\section{FRAMEWORK FOR ROAD MANAGEMENT}

\subsection{Road Network Management}

Road network management aims to optimise the performance of the road network over the life-cycle of its component infrastructure assets (Robinson, 2008). In essence, it is a process that seeks to maintain and improve the performance of the existing infrastructure asset system. Road network management is a key strategic approach enabling road authorities to optimise the performance of their assets.

Robinson (2008) presents an overall framework for network management broken down into four decision levels:

1. Strategic planning;

2. Programming;

3. Preparation; and

4. Operations management.

Strategic planning involves long-term estimates of expenditure in order to achieve predefined levels of service under various budgetary scenarios. These are of strategic interest to senior policy makers and the work is typically carried out by planning or economics units within the agency though some agencies may choose external consultants to develop these estimates. Programming activity produces estimates of expenditure for different treatment types, years and road sections, prioritising works to find best value for money. In the preparation phase, projects are prepared for implementation with detailed specifications and costing with potential re-estimates of cost-benefit calculations. In the final, operational management phase, activities focus on individual road sections and decisions are made on a daily basis by technicians or supervisors.

The above framework is useful in understanding the relationship between asset management and strategic decision-making and policy. Asset management operates at three different levels: strategic, tactical and operational. These levels are comparable with the road network management functions described above. The framework for road management provides a basis for understanding how asset management should be an integral part of the wider policy and strategy, not a separate or independent tool of the road authority. Asset management is a critical sub-component of wider policy objectives and, conversely, objectives of asset management are derived from these strategic plans. Asset management should have a direct relationship to policy, strategy and funding. Policy defines what is being optimised, strategy is the means by which the policy is implemented and defines responsibilities and means for doing this. 


\subsection{Asset management}

Asset management strategies operate at different levels of assets and asset systems. At the top level, there is a need to manage an asset portfolio - here capital investment value, performance and sustainability are key concerns. At the intermediate level, there is a need to manage asset systems within the overall asset portfolio - here system or network performance, risk optimisation and costs are key concerns. Finally, there is a need to manage specific assets and asset sub-components - here asset lifecycle costs, performance and risks are crucial considerations (IAM 2012).

Asset management is often misleadingly understood as maintenance management. This definition, however, is too narrow. Asset management is related to delivering pre-defined goals, normally measured in terms of outcomes or service levels. The definition of asset management according to the American Association of State Highway and Transportation Officials (AASHTO 2011) is a useful starting point:

"Transportation Asset Management is a strategic and systematic process of operating, maintaining, upgrading and expanding physical assets effectively throughout their lifecycle. It focuses on business and engineering practices for resource allocation and utilization, with the objective of better decision making based upon quality information and well-defined objectives."

Though it highlights the importance of full lifecycle approaches, this definition still lacks the service-focus which is clearer in the definitions provided by the Australian and New Zealand international infrastructure manual (IIMM 2011):

"a plan developed for the management of one or more infrastructure assets that combines multi-disciplinary management techniques (including technical $\&$ financial) over the life cycle of the asset in the most cost effective manner to provide a specific level of service."

and the UK County Surveyor's Society (UK CSS 2004):

"a strategic approach that identifies the optimal allocation of resources for the management, operation, preservation and enhancement of the highway infrastructure to meet the needs of current and future customers."

According to these definitions, the overall aim of asset management is to optimise the service level delivered by infrastructure over its life-cycle. The focus of management should be on value to users or customers and not solely, nor even primarily, on cost or asset-replacement cost perceived by the infrastructure provider.

The optimisation of the service level of infrastructure requires (adapted from Robinson, 2008):

- Assessing condition and monitoring performance;

- Predicting demand;

- Failure mode analysis, risk assessment and management;

- Demand management; and 
- Optimizing decision-making.

These critical elements can be situated in a broader asset management planning process (Figure 2).

Figure 2. Asset Management Planning Process

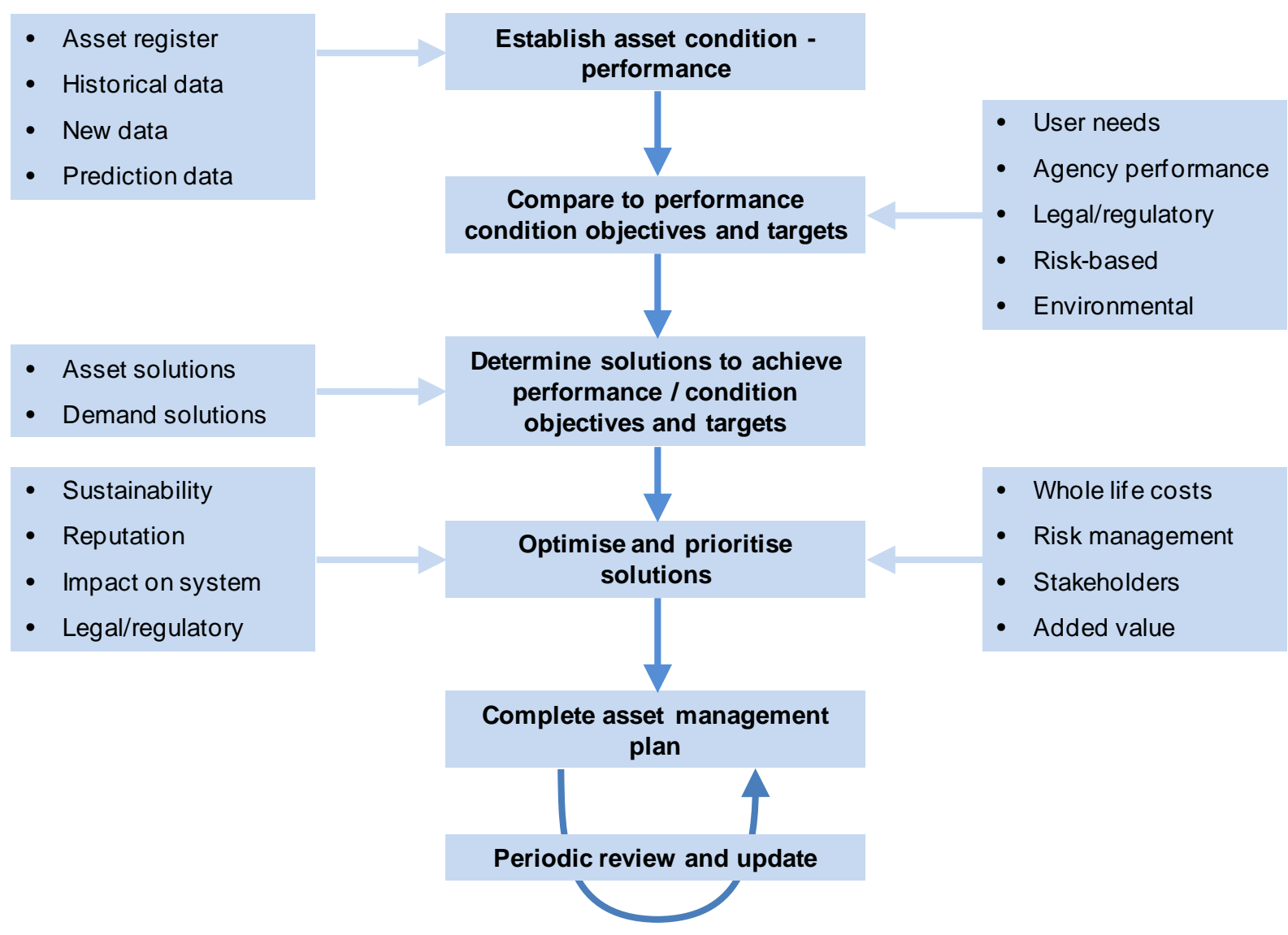

Source: based on CIRIA (2009).

Knowledge of existing assets (condition and performance) enables the prediction of future needs in order to bridge the gap between existing conditions and the desired level of service. Knowing current performance enables predictions of future interventions. Developing performance measures, monitoring performance and identifying factors affecting level of service is fundamental to asset management. This information is required for life-cycle planning and for effective prioritisation of maintenance decisions under budget constraints.

It is crucial to understand not only current demand levels but how this is likely to evolve in the future. This requires identifying trends likely to influence demand for and impact upon assets. These trends include changes in policy priorities, demography, technology, environment and income and necessarily entail some level of uncertainty that must be identified and addressed. 
Another form of uncertainty that must be identified and explicitly accounted for involves asset performance under evolving conditions that may surpass asset design specifications. The primary risk here involves changing climatic conditions over the lifetime of the asset or its sub-components. Asset design specifications are based on historic, largely stable, climate regimes yet evidence indicates that these are evolving with potentially broad impacts on infrastructure assets. Ensuring that lifecycle asset and asset system meet performance objectives will require risk identification and mitigation strategies that suitably address uncertainty related to climate impacts.

Failure mode and impact analysis are important methods for designing and prioritising preventive maintenance activities and are often used as the basis for preventive maintenance planning. Effective and sustainable management of assets inherently includes the proactive management of risks to the asset. Transport agencies manage complex infrastructure assets. Failure of these assets and concomitant impacts on safety or network disruption is not an acceptable option.

\section{Table 1. Example of Risk Assessment Matrix}

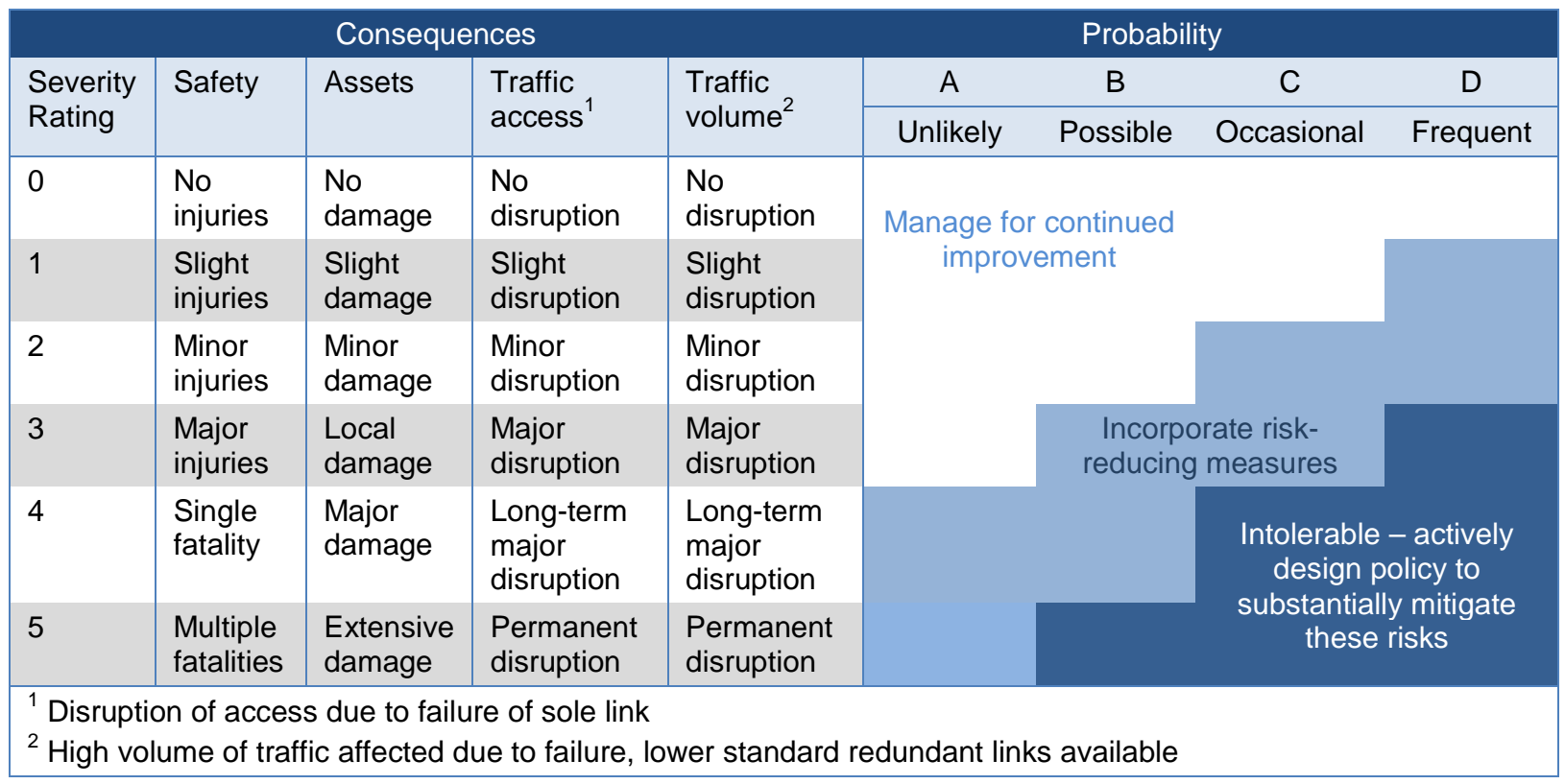

Source: Adapted from DNV (2001)

Risk identification and management strategies seek to match preventative action with the balance of consequences and probabilities of failure. Asset failures can have multiple consequences (Table 1) and these should be each assessed according to the severity of their impacts and their probabilities. Consequences may be constrained to a single, non redundant but low-traffic link or may be system-wide, impacting major traffic flows on many parts of the network. Risk assessment should also account for simultaneous or rapid sequential failures - most severe disruptions can be traced to multiple compounded incidents.

The National Cooperative Highway Research Program (NCHRP) has carried out a survey of state transportation agencies about implementation of risk management practices in the United States. According to the report of the 43 respondents, only 13 have formalized agency level risk management and fewer had risk management at the agency, program and project level. 
The Federal Highway Administration corporate risk assessment identified seven areas of "threat risks" and four areas of "opportunity risks" (FHWA 2010). The threat risks included the following:

- Risks due to infrastructure failure;

- Internal FHWA capacity failure (lack of succession planning and skilled people, knowledge and systems); and

- Lack of data integration and security that could compromise decisions.

Opportunity risks include:

- Addressing mobility and freight;

- Continuing to address safety and decreasing deaths and injuries on national roads;

- Deploying innovations and accelerating technology to continue to shorten project delivery periods; and

- Increasing transparency and fiscal accountability in investment decisions affecting condition and performance of the transportation system.

Demand management measures may include traffic signal controls, speed controls, road pricing etc. It is also important to predict the effects of policies on demand in the future. The objective then is to optimise the performance of existing assets and reduce the need for new assets to meet rising or changing demand.

Decision-making should be optimised in order to select the most appropriate (optimal) treatment taking into account desired level of service required and the assets themselves. The optimisation problem involves trading off road agency costs against road user costs over time. In case of road maintenance, the three main components of the optimisation problem are 1) prediction of future pavement condition, 2) prediction of the effect of any treatment on road condition, and 3 ) estimation of road user costs as a function of road condition (Harvey 2012). This allows then for identifying the best possible treatment option while optimising also the use of the available budget. 


\section{PERFORMANCE-BASED ASSET MANAGEMENT}

Defining and measuring required service levels is a fundamental starting point for asset management and many road authorities use an outcome-oriented and performance based approach to network management (Karlaftis and Kepatsoglou, 2012). As an international review of best practices for road management shows, agencies today are moving toward a service-based approach for managing road networks and are moving away from a strictly condition-based approach (ISST 2012). Customer-driven priorities, such as safety, reliability, comfort, have become the primary drivers for road maintenance and renewal options. This has had a fundamental impact on the types of data collected and the performance targets used in maintenance and renewal programs around the word (ISST 2012).

There is a strong synergy between the basic principles of asset management and those of performance management. Indeed, the term asset management can be used to describe a performance-based approach for managing road assets (Cambridge Systematics, 2011). Setting performance objectives and associated indicators is an integral element of road management tools. A key component of any road project or program is a well-

defined set of goals and objectives (OECD, 2001).

Performance measures and related data collection procedures are critical to successful asset management. Figure 3 presents the basic framework for asset management decision-making for resource allocation and use and illustrates how performance measures relate to the management cycle. Performance measures and related targets act as practical expression of policy objectives. They reflect customer expectations and funding targets and serve as criteria for decision making and as a basis for measuring system performance.

Figure 3. Asset management framework

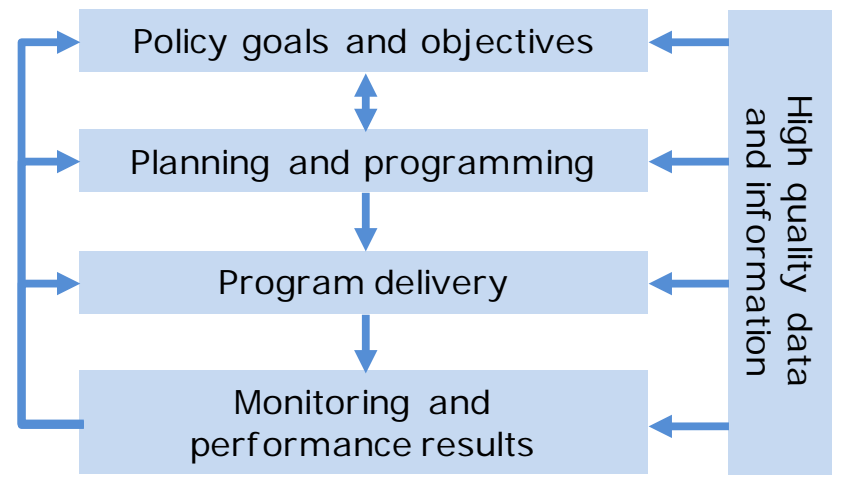

Source: Based on NCHRP (2006). 
Optimal service levels are not a static construct. They evolve over time (both over the short- and long-term) and in response to a number of interacting factors (Figure 4). These may include changing demands by asset users, new legislative or regulatory requirements, changes in the available budget or new or exacerbated risks. As service level expectations and targets change, so too do the options for delivering those targets - what may not have been considered a feasible or desirable option in the past may become the preferred option as service level expectations evolve.

Figure 4. Dynamic interactions between service level targets and asset management objectives and strategies

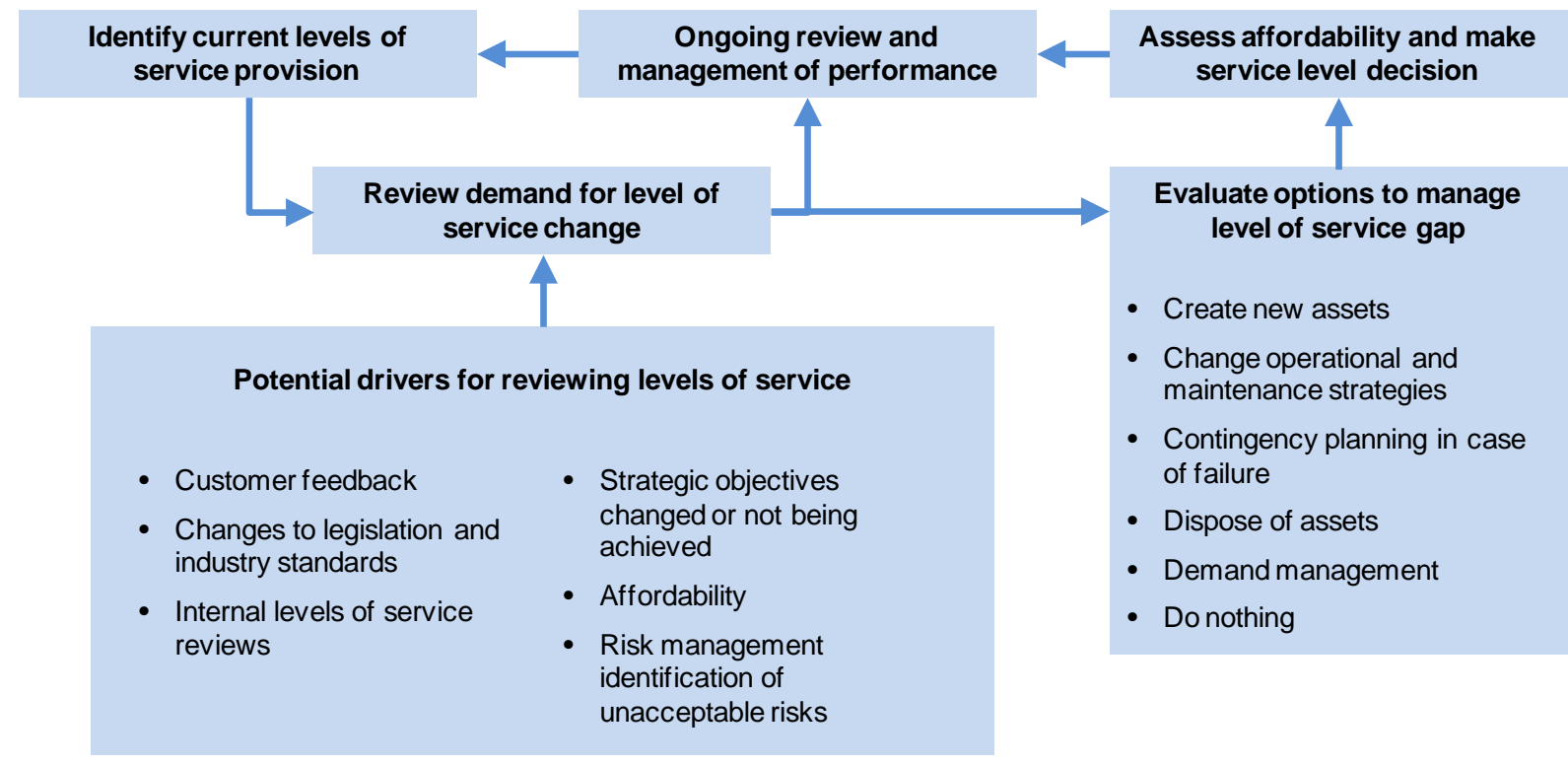

Source: UK Audit Commission (2000).

Karlaftis and Kepatsoglou (2012) review road management indicators applied in the OECD countries. They conclude that the taxonomy of indicators remain similar for most parts of the world, including infrastructure preservation, safety and security, environmental sustainability, mobility and accessibility and economy. Performance targets, on the other hand, are set on a case-by-case basis.

There is, however, a trade- off between costs and benefits of providing different measures. In some cases, an over-complex performance measurement hinders a meaningful analysis of results. Traditionally, performance measures have been biased towards technical aspects of infrastructure (such as roughness) but recent years have brought a number of output related indicators (e.g. journey times) reflecting the economic value of infrastructure and its use. Indeed, there is a need to move towards policy related measures derived from technical ones.

Harmonisation of performance indicators and targets across countries may be a difficult task but could prove useful for benchmarking and helping to revise procedures and approaches. 


\section{THE COST OF MAI NTENANCE DEFERRAL}

Funding for road maintenance is often postponed when budgets are tight because a lack of maintenance does not necessarily lead to immediate failure of the network. However, maintenance deferral can be expensive in the long term. Short-term cost savings from deferring maintenance may be overweighed, even in present value terms, by the consequent need for more expensive treatments in the future.

Deferred maintenance refers to the dollar amount of maintenance and rehabilitation work that should have been completed to maintain the pavements in acceptable condition but had to be deferred due to reduced maintenance funding or policy changes for the preventative maintenance and/or pavement rehabilitation programs. Pavements that remain untreated can deteriorate at a faster rate. The cost of repairs increases disproportionately as the condition of the pavement decreases over its life. Deferring pavement preventive maintenance or rehabilitation can lead to a substantial increase in required repair costs (FHWA 2005).

Most highway agencies face the situation where their funding needs for maintenance and rehabilitation activities exceed the available budget. As a result, they have no choice but to reduce the levels of service their roads provide to users. The situation is far more serious when budget constraints are tight to the point that road agencies cannot carry out the required routine and preventive maintenance activities that extend pavement life by slowing down the deterioration processes. Failure to apply these treatments leads to more rapid deterioration of the pavements such that expensive rehabilitation actions will be required in the future if the road is to continue to perform its current functions. The alternative is to allow the road to deteriorate to the point that road users are forced to travel by alternative routes or relocate.

The optimisation of road maintenance in its purest form involves trading off agency or maintenance costs against user costs over time. For economic analysis of investment decisions, the optimisation problem is specific in terms of welfare maximisation. For maintenance, it is specified in terms of minimising the present value of combined road agency and road user costs. Road agency costs are usually budget constrained. There are alternative approaches such as minimising agency costs to achieve minimum standards (see Harvey 2012 for more detailed discussion on the optimisation problem and approaches to maintenance optimisation). Models such as the World Bank's Highway Development and Management Model (version 4) can be used to assist with the determination of road user and road agency costs. This model simulates pavement deterioration, maintenance costs and road user costs as a function of road characteristics and pavement condition (Kerali, 1999).

Although most highway administrators acknowledge the fact that pavement preservation is perhaps the most effective way of using the limited budgets available, the costs associated with deferring maintenance actions is oftentimes overlooked when establishing performance goals for the system. 
In the long term, deferring maintenance can make roadway costs much greater than indicated by current spending levels. The challenge is to provide additional information on the value of roadway facilities and the costs associated with deferred maintenance spending. In particular, it is to quantify the costs of underfunding in order to bring these costs to the attention of decision makers.

Harvey (2012) proposes a way for communicating the cost of maintenance deferral to decision makers through a measure termed the "equivalent interest rate for deferred maintenance" (EIRDM). He sees deferring maintenance as a form of borrowing. Funds are saved in the short-term at the expense of higher outlays in the future. Estimating an EIRDM enables comparisons to be made between cost of borrowing through maintenance deferral and conventional borrowing to fund current expenditures on maintenance.

\section{OPTI MAL CONTRACTI NG}

Road administrations have evolved over time with the aim of increasing the efficiency and the effectiveness of organizations and the transport sector. This evolution from a traditional construction and maintenance organization to corporatization of client organization (Talvitie 1997) has also played role in increasing interest in the private finance of road infrastructure.

A significant part of the maintenance and operations activities are currently outsourced in most of the European countries. A recent survey carried out by the Conference of European Directors of Roads shows that the proportion of outsourced work to total expenditure ranges from $60 \%$ in Denmark and the Netherlands to $100 \%$ in Sweden, Spain and the United Kingdom (CEDR 2010). The same report indicates that contractors carry out most of the work on roads while the national road authorities make the decisions. In order to reduce in-house activities, countries use increasingly performance contracts where administration lays down less technical specifications (CEDR 2010).

There are several ways of designing contracts for tendering maintenance and construction. Nilsson (2012) specifies four different contract designs and compares these different alternatives, namely complete un-bundling, Design-Build, performance contract, and Public-Private Partnership.

By complete un-bundling (Design-Bid-Build) one refers to a contract in which each task is separately procured. A further feature of the Design-Bid-Build approach is that the tendering process ends with each entrepreneur submitting a unit price for each input required. Complete un-bundling is still the most common approach to contracting in infrastructure. One possible reason for its popularity is the ability for tendering agency to specify exactly the way the asset is being built. On the other hand, there are concerns for over-specification of projects possibly reflecting lack of expertise in the public sector.

In order to minimize design costs, the complete un-bundling requires that the tendering agency is fully informed about relevant aspects of the project, including prices for items 
used in construction. This assumption of full information becomes more unrealistic as complexity of project increases. This is the main motive for Design-Build construction contract, which describes the overall qualities, such as alignment, width and other characteristics, of the infrastructure to be built. This type of contract focuses more on the output to be delivered rather than inputs and leaves room for innovation on how the asset should be built.

A performance contract combines design, construction, maintenance and renewals into one contract. The performance contract is signed with a fixed price of construction cost while controlling quality through specification of target service levels and conditioning payment on meeting these targets. Performance based maintenance is considered as a modern approach for achieving cost effective road maintenance and operations projects. However, selection and measurement of appropriate indicators is critical for implementing performance based contract successfully (Karlaftis and Kepatsoglou, 2012). Harvey (2012 and 2013) present a scheme in which generalized user costs are used as a performance measure. The penalties for under-performance and bonuses for over-performance equal their marginal social values.

The fourth way of designing contracts, Public-Private-Partnership, is rather a combination of bundling and external funding. The PPP contract provides a further lever to reduce the risk of reduced quality from the holder of the contract.

As Nilsson (2012) concludes, there is no one type of contract for all situations but the type of contract depends on specific circumstances of individual projects. This emphasises the importance of the preparatory phase of a new project. The tendering agency must have tools available to assess which contracting approach will deliver the project at the lowest possible cost over the life-cycle of the infrastructure. International organisations or financial institutions (e.g. OECD or World Bank) could establish such a framework for value for money analysis for public authorities to encourage quantification of benefits in monetary terms. 


\section{BI BLI OGRAPHY}

AASHTO (2011), Transportation Asset Management Guide, A Focus on Implementation, American Association of State Highway and Transportation Officials, January 2011.

CCS (2004), Guidance Document for Highway Asset Management, United Kingdom County Surveyors' Society, Shrewsbury, United Kingdom.

CEDR (2010), Report on BEXPRAC, Conference of European Directors or Road, March 2010.

CIRIA (2009), Whole-life Infrastructure Asset Management: Good Practice Guide for Civil Infrastructure, CIRIA C677, Construction Industry Research and Information Association, London, United Kingdom.

Cook, A. (2011), A fresh start for the Strategic Road network, Managing our roads better to drive economic growth, boost innovation and give road users more for their money, Department for Transport, November 2012.

DNV (2001), Marine Risk Assessment, Det Norske Veritas, Offshore technology report 2001/063, London, United Kingdom

ECMT (2007), Transport Infrastructure Charges and Capacity Choice, Self-Financing Road Maintenance and Construction, Round Table 135, OECD, 2007.

FHWA (2012), Report 2: Managing Asset Risks at Multiple levels in a Transportation Agency, U.S. Department of Transportation, Federal Highway Administration, August 2012.

FHWA (2010), Federal Highway Administration Risk Management, Corporate Risk Assessment, December, 2010.

FHWA (2007), Asset Management, U.S. Department of Transportation, Federal Highway Administration.

Harvey, M. (2013), Commercial Road Supply with Incentive Regulation, International J ournal of Sustainable Transportation, forthcoming.

Harvey, M. (2012), Optimising Road Maintenance, International Transport Forum Discussion Paper 2012-12, OECD, 2012.

IAM (2012), Asset Management - an Anatomy (Version 1.1), Institute of Asset Management, Bristol, United Kingdom, February 2012.

II MM (2011), International I nfrastructure Management Manual. 
ISST (2012), Managing Pavements and Monitoring Performance: Best Practices in Australia, Europe and New Zealand, International Scanning Study Team, August 2012.

OECD/ITF (2010), Trends in the Transport Sector 1970-2010, OECD 2012.

Karlaftis, M. and Kepaptsoglou, K. (2012), Performance Measurement in the Road Sector: A Cross-Country Review of Experience, International Transport Forum Discussion Paper 2012-10, OECD, 2012.

Kerali, H. (1999), Overview of HDM-4, The Highway Development and Management Series, Volume 1, World Road Association, Paris.

McKenzie Global Institute (2013), Infrastructure Productivity: How to Save a \$1 Trillion a Year, McKenzie \& Company, January 2013

NCHRP (2006), Performance Measures and Targets for Transportation Asset Management, National Cooperative Highway Research Program, Report 551, Transportation Research Board, Washington, D.C.

NCHRP 20-24 (74), AASHTO, Executive Strategies for Risk Management by State Departments of Transportation.

Nemoto, T. (2012), The Charging Principle for the Development and Maintenance of Transport Infrastructure, Hitotsubashi University, Working paper Series No. 141, October 2012.

Nilsson, J.-E. (2012), Procurement and Contract Design in the Construction Industry... not one size fits all, International Transport Forum Discussion Paper 2012-11, OECD, 2012.

OECD (2009), Measuring Capital - OECD Manual 2009: Second edition, OECD, Paris.

OECD (2001), Asset Management for the Roads Sector, OECD, Paris.

Robinson, R. (2008), Restructuring Road Institutions, Finance and Management, Volume 1: Concepts and Principles, University of Birmingham, 2008.

Robinson, R. and Roberts, P. (1982), The cost-effectiveness of road maintenance, Third African Highway Maintenance Conference, Addis Ababa, September 1982.

Talvitie, A. (1997), International Experiences in Restructuring Road Sector, Transportation Research Record 1558, pp. 99-107.

UK Audit Commission (2000), Aiming to Improve: The Principles of Performance Measurement, United Kingdom Audit Commission, LMP 1400, London, United Kingdom

UK Highways Agency (2011), Climate Change Risk Assessment, United Kingdom Department for Transport, August 2011

WRA (2012), Road Maintenance Review, International Comparison, World Road Association United Kingdom, May 2012. 
